\title{
Diabetes Mellitusun Donuk Omuz Tedavisinde Uygulanan Interskalen Blok Altında Rehabilitasyon Başarısına Etkisi - Retrospektif Çalışma
}

\author{
Teoman ATICI \\ Bursa Uludağ Üniversitesi Tıp Fakültesi Ortopedi ve Travmatoloji Anabilim Dalı, Bursa.
}

\begin{abstract}
ÖZET
Donuk omuz, omuzun hareket kısıtlılığı ile seyreden ve ağrıya yol açan bir hastalığıdır. Kas iskelet sistemi patolojileri içinde ilk sıralarda yer alır.Çalıșmanın amacı bir risk faktörü olan diabetesmellitusun (DM) donuk omuz tedavisinde uygulanan interskalenkateter altında egzersize etkisini incelemektir. 2014-2019 yılları arasında donuk omuz şikayetiyle başvuran ve interskalen blok altında egzersiz tedavisi alan 21 hasta (16 kadın 5 erkek) fizik muayene değerlerive klinik bulguları ile retrospektif olarak değerlendirildi. İșlem sonrası minimum değerlendirme süresi 6 aydı. Hastalar risk faktörü olan DM tanılı olanlar ve olmayanlar olarak 2 gruba ayrıldı. (13 diabetsiz-8 diabetli) Ortalama yaş 59,4 (min42 -max 86) idi. İki hasta grubunun blok öncesi ve son izlemdeki omuz hareket açıklıkları ve fonksiyonel durumları goniometrik ölçüm ve UCLA (University of California Los Angeles) anketi kullanılarak ölçüldü. Sonuçlar istatistiki olarak analiz edildi. Yapılan istatistik sonucunda her iki grubunda interskalen blok uygulamasından anlamlı yarar gördüğ̈̈ gözlendi. Diabetin eşlik etmediği donuk omuz tanılı hastaların EHA (Eklem Hareket Açıklığı) ve UCLA skorlarındaki iyileşmenin diabetli hastalarınkinden anlamlı olarak fazla olduğu görüldü $(p<0,05)$. Donuk omuzun en sık görüldüğü yaş, aktif orta yaştır. Sosyo-ekonomik kayıpları en aza indirmek için hastaların erken dönemde çalışma ve sosyal yaşantılarına dönmesi önemlidir. Tedavide anestezi altında manipülasyon kullanılabilmektedir fakat anestezinin etkisi geçtikten sonra manipülasyondaki kazanımın ciddi bir kısmı kaybedilmektedir. Bunu engellemek için interskalen blok kateteri (kontrollü aneljezi) altında rehabilitasyon hedeflenmektedir. DM’lu donuk omuzun prognozu daha kötüdür. İnterskalen blok altında rehabilitasyon donuk omuzun etyolojisinden bağımsız olarak hareket açıklığında ve fonksiyonda anlamlı iyileşme sağlamaktadır. DM'lu hastaların son kontrollerindeki gerek hareket açıklıkları, gerekse fonksiyonel skorları DMlu olmayanlardan istatistiksel olarak daha kötüdür.
\end{abstract}

Anahtar Kelimeler: Donuk Omuz. DiabetesMellitus. İnterskalen Blok Kateter. Omuz Rehabilitasyon. Anestezi altında egzersiz.

The Effect of Diabetes Mellitus on Rehabilitation Success Under Interscalene Block in Frozen Shoulder Treatment - A Retrospective Study

\begin{abstract}
Frozen shoulder(FS) is one of the most important musculoskeletal diseases that causes severe pain and loss of joint motion. The aim of this study is to observe the effect of diabetes mellitus(DM) on exercise under the interscalene block in the treatment of frozen shoulder. Twentyone patients (16 females, 5 males) with frozen shoulder who were treated with exercise under interscalene block between 2014-2019 were evaluated retrospectively. The minimum postoperative follow-up was 6 months. The patients were divided into two groups as those with and without DM (13 without DM-8 DM). The mean age was 59.4(min 42 -max 86). Shoulder range of motion and functional status wereevaluated using goniometric measurement and UCLA questionnaire before the block and at the last follow-up. The results were analyzed statistically. As a result, it was observed that rehabilitation with interscalene block catheter useful for both groups. Interscalene block has better results for non-diabetic frozen shoulders than diabetics $(\mathrm{p}<0.05)$. FS is most prevalent in the active-middle age. Early rehabilitation is vital to reduce the detrimental socio-economic effects of the disease. Manipulation under anesthesia is effective to improve range of motion but a significant degree of gain is lost once anesthesia is over. To minimize this, rehabilitation may be performed using interscalene block catheter. Prognosis of FS in patients with DM is worse than other etiologies. Rehabilitation under interscalene block provides significant improvement in range of motion in all patients with FS. Improvement in both the range of motion and functional scores of the patients with DM isless than those without DM.
\end{abstract}

Key Words: Frozen Shoulder. Diabetes Mellitus. Interscalene Block Catheter. Shoulder Rehabilitation. Shoulder Excersises Under Anesteshia.

Geliş Tarihi: 07.Ekim.2019

Kabul Tarihi: 30.Mart.2020

Dr. Teoman ATICI

Bursa Uludağ Üniversitesi Tıp Fakültesi

Ortopedi ve Travmatoloji A.B.D.

Tel: 05323065511

E-posta: teoman@uludag.edu.tr
Donuk omuz, glenohumeral eklemin ileri derece hareket kısıtlılığı ile seyreden, şiddetli ağrıya ve fonksiyonel kayba yol açan bir hastalığıdır. Kendi kendini sınırlayıcı bir karakteri olan bu rahatsızlık sanıldığının aksine ağrılı kas iskelet sistemi patolojileri içinde görülme sıklığı olarak ilk sıralarda yer alır ${ }^{1}$. İlk olarak 1872 yılında Duplay² tarafindan "skapulohumeral 
periartrit" olarak tanımlanan bu hastalığ Codman $^{3}$ 1934'te “donuk omuz" şeklinde isimlendirmiştir. Aradan geçen bunca süreye rağmen hastalığın etyopatogenezi tam olarak aydınlatılamamıştır. Bu hastalarda klinik tabloya sıklıkla eşlik eden ve etyolojide rol oynadığ1 düşünülen sistemik faktörler içinde diabetes mellitus, hiperlipidemiler, tiroid metabolizması bozuklukları ve hipoadrenalizm yer alır.

Her ne kadar donuk omuz etiyopatogenezi tartışmalı olsa da, hastalığın klinik tablosu oldukça tipik ve kısıtlayıcıdır. Glenohumeral eklemdeki ağrı sebebi ile hasta omuz hareketlerini istemli olarak azaltmış ve korumaya almıştır. Çekilen röntgenlerde kemik yapılarda herhangi bir patolojiye rastlanmaz. Hastalığın çeşitli evrelerinde alınan patolojilerde eklem kapsülünde kronik inflamasyon, kapsül kalınlığında artma, kapsül-cerrahi boyun yapışıklıkları ve ilerleyici fibrozis görülmesi sebebi ile Neviaser tarafindan "adhezivkapsülit” olarak da adlandırılmıştır",5. Eklem kapsülü ve çevre dokulardaki kontraktürler sebebi ile hem aktif hem de pasif omuz hareketleri tüm yönlerde ileri derece kısıtlanmıştır. Hastanın omzunda tama yakın fonksiyon kaybı vardır ${ }^{6}$.

Donuk omuz olguları altta yatan patoloji olup olmamasına göre primer ya da sekonder olarak sınıflandırılabilir. Sekonder tipe yol açan sebepler içinde diabetes mellitus önemli bir yer tutar. Özellikle insülin bağımlı vakalarda kisitlılık daha belirgindir ve prognoz daha kötüdür $^{7,8}$. Biz de kendi klinik tecrübemizde interskalen blok, hasta kontrollü analjezi, anestezi altında manipülasyon ve cerrahi gevşetme uygulanan diabetik hastaların fonksiyonel sonuçlarının diabetik olmayanlara kıyasla daha kötü olduğunu farkettik. Hipotezimizi test etmek için bu retrospektif klinik çalışmayı dizayn ettik.

\section{Materyal ve Metod}

Yerel etik kuruldan gerekli izinin alınmasını takiben, minimum 6 aylık konservatif tedaviye cevap alınamaması üzerine 2014-2019 yılları arasında ameliyathanede interskalen blok ve sonrasında hasta kontrollü analjezi ile egzersiz programına alınan donuk omuz tanılı hastalar retrospektif olarak incelendi. Omuz çevresi kırık öyküsü olan, donuk omuz öncesinde görüntüleme yöntemleri ile tespit edilmiş eklem içi ya da rotator manşet patolojileri olan, diabet dışında sistemik donuk omuz sonuçlarını etkileyecek metabolik komorbiditelere (hipotiroidizm, hipertiroidizm) sahip, kateter uygulaması sonrası uygulanan egzersizlere uyum göstermeyen ya da tedavi sürecini reddeden hastalar çalışma dışı bırakıldı.

Çalışma kriterlerini karşılayan ve en az 6 aylık klinik takibi olan toplam 21 hasta çalışmaya dahil edildi. Hastaların 16'sı kadın, 5'i erkekti. Ortalama yaş 59,4 yıl idi (42-86). Hastaların 7'si iş hayatına devam eder- ken, 14'ü emekli ya da ev kadını idi. 6 hastanın sağ, 15 hastanın sol omuzunda hareket kısıtlılığ 1 vardı. 5 hastanın dominant, 16 hastanın ise dominant olmayan ekstremitelerinde donuk omuz görüldü (Tablo I). Hastalar diabetli olup olmamalarına göre iki gruba ayrıld1. Her iki hasta grubunun blok öncesi ve son izlemlerindeki omuz hareket açıklıkları ve fonksiyonel durumları goniometrik ölçüm ve UCLA hasta memnuniyet anketi kullanılarak ölçüldü. İki grup arasında blok öncesi fark olup olmadığı ve tedaviden gördükleri fayda istatistiksel olarak incelendi.

Tablo I. Hastaların demografik verileri

\begin{tabular}{|l|l|c|}
\hline \multicolumn{2}{|l|}{ Hasta Sayısı } & 21 \\
\hline \multirow{2}{*}{ Cinsiyet } & Kadın & 16 \\
\cline { 2 - 3 } & Erkek & 5 \\
\hline Yaş & 59,4 (42-86) \\
\hline Meslek Sahibi Olan & 7 \\
\hline \multicolumn{2}{|l|}{ Takip Süresi } & 14,2 ay (6-32) \\
\hline \multirow{2}{*}{ Diabetes Mellitus } & Var & 8 \\
\cline { 2 - 3 } & Yok & 13 \\
\hline \multirow{2}{*}{ Etkilenen Taraf } & Dominant Omuz & 5 \\
\cline { 2 - 3 } & Dominant Olmayan Omuz & 16 \\
\hline $\begin{array}{l}\text { Diğer Omuzda da } \\
\text { Semptom Olan }\end{array}$ & \multicolumn{2}{|l}{} \\
\hline
\end{tabular}

Hasta analizlerinin istatistiki değerlendirmesinde verinin normal dağılım gösterip göstermediği ShapiroWilk testi ile incelendi. Normal dağılım gösteren verinin karşılaştırılmasında iki fazla grup için t testi normal dağılmayan veri için Mann Whitney testi, Nitel verilerin analizinde Fisher'in kesin ki-kare testi kullanıldı. Tekrarlı ölçümlerin grupiçi karşılaştırılmasında Wilcoxon işaret sıra testi kullanıldı. Tekrarlı ölçümlerin gruplar arası karşılaştırmasında son ölçümdeki değişim fark değerleri alınarak karşılaştırma yapıldı ve anlamlılık düzeyi $\alpha=0.05$ olarak belirlendi. Verinin istatistiksel analizi IBM SPSS23.0 istatistik paket programında yapılmıştır.

\section{Skalen Blok Uygulaması}

Hastalara ameliyathane koşullarında gerekli arıtım ve örtümü takiben aynı kıdemli anestezi doktoru tarafından interskalen blok uygulandı ve kalıcı kateter yerleştirildi. Cerrah tarafindan anestezi altında omuz manipüle edildi ve hareket açıklığı tama yakın sağlandı. Hastaların cerrahi sonrası dönemde kullanmaları için kalıcı katetere hasta kontrollü analjezi cihazı bağlandı.

Hastalara bloğun geçmesini takiben aynı gün içinde eklem hareketlerine yönelik rehabilitasyon programı düzenlendi. Egzersizden 30 dakika önce analjezik infüzyonu başlanan hastalara fizyoterapist eşliğinde aktif ve pasif eklem hareket açıklığı egzersizleri başlandı. Bir hafta süre ile interne edilen hastalar ev egzersiz programı verilerek taburcu edildi ve blok sonras1 1. ayda poliklinik kontrolüne çağrıldı. Ortalama takip süresi $14^{(6-32)}$ aydı (Tablo I). Yapılan poliklinik 


\section{Diabetes Mellituslu Hasta; Donuk Omuz ve İnterskalen Blok}

kontrollerde hastaların eklem hareket açıklıkları ölçüldü ve UCLA hasta anketi kullanılarak fonksiyonel durumları değerlendirildi ${ }^{10}$.

\section{Sonuçlar}

Her iki hasta grubunda da kateter takılması sonrası omuz abdüksiyon, fleksiyon, iç rotasyon ve dış rotasyonda anlamlı artış gözlendi (Tablo II, Tablo III). $(\mathrm{p}<0,05)$.

Tablo II. Diabetli hastalarda blok öncesi ve son kontrollerdeki eklem hareket açıklıkları

\begin{tabular}{|c|c|c|c|c|}
\hline & $\begin{array}{c}\text { İşlem } \\
\text { Öncesi } \\
\text { EHA }\end{array}$ & $\begin{array}{c}\text { İşlem Sonrası } \\
\text { Takiplerdeki } \\
\text { EHA }\end{array}$ & $\begin{array}{c}\text { İşlem Öncesi } \\
\text { ve Sonrası } \\
\text { EHA-Değişim }\end{array}$ & $\begin{array}{c}\text { Anlamlılık } \\
P<0,05\end{array}$ \\
\hline Abdüksiyon & $5,87(0-15)$ & $108,75(70-140)$ & $\begin{array}{c}102,8 \\
(66-138)\end{array}$ & 0,012 \\
\hline Fleksiyon & $5,25(0-11)$ & $\begin{array}{c}125,6 \\
(100-150)\end{array}$ & $\begin{array}{c}120,3 \\
(144-98)\end{array}$ & 0,012 \\
\hline İç Rotasyon & $5,25(2-8)$ & $56,8(45-75)$ & $\begin{array}{c}51,6 \\
(37-69)\end{array}$ & 0,012 \\
\hline $\begin{array}{c}\text { Dış } \\
\text { Rotasyon }\end{array}$ & $3,5(0-6)$ & $\begin{array}{c}60,6 \\
(45-70)\end{array}$ & $\begin{array}{c}57,1 \\
(45-69)\end{array}$ & 0,012 \\
\hline
\end{tabular}

EHA: Eklem Hareket Açıklı̆̆ı

Tablo III. Diabeti olmayan hastalarda blok öncesi ve son kontrollerdeki eklem hareket açıklıklar1

\begin{tabular}{|c|c|c|c|c|}
\hline & $\begin{array}{c}\text { İşlem } \\
\text { Öncesi } \\
\text { EHA }\end{array}$ & $\begin{array}{c}\text { İşlem Sonrası } \\
\text { Takiplerdeki } \\
\text { EHA }\end{array}$ & $\begin{array}{c}\text { İşlem Öncesi } \\
\text { ve Sonrası } \\
\text { EHA-Değişim }\end{array}$ & $\begin{array}{c}\text { Anlamlılık } \\
\mathrm{P}<0,05\end{array}$ \\
\hline Abdüksiyon & $8,3(0-15)$ & $\begin{array}{c}148,4 \\
(120-170)\end{array}$ & $\begin{array}{c}140 \\
(105-170)\end{array}$ & 0,001 \\
\hline Fleksiyon & $7,2(0-12)$ & $\begin{array}{c}155,3 \\
(130-175)\end{array}$ & $\begin{array}{c}148,15 \\
(120-172)\end{array}$ & 0,001 \\
\hline İç Rotasyon & $5,6(0-10)$ & $\begin{array}{c}75,7 \\
(60-90)\end{array}$ & $\begin{array}{c}70,15 \\
(55-85)\end{array}$ & 0,001 \\
\hline $\begin{array}{c}\text { Dış } \\
\text { Rotasyon }\end{array}$ & $3,8(0-10)$ & $\begin{array}{c}74,5 \\
(60-90)\end{array}$ & $\begin{array}{c}70,6 \\
(55-85)\end{array}$ & 0,001 \\
\hline
\end{tabular}

EHA: Eklem Hareket Açıklığı

Diabeti olmayan hastalarda kateter uygulaması sonrası eklem hareket açıklıklarında oluşan artışın diabeti olan ve kateter uygulanmış olan hastalarda gözlenen eklem hareket açıklığındaki artışa göre anlamlı şekilde fazla olduğu gözlendi $(\mathrm{p}<0,05)$. (abdüksiyon p-skor: 0,002, fleksiyon p-skor:0,003, iç rotasyon p-skor:0,002, diş rotasyon p-skor:0,003)

Hastaların klinik sonuçlarının değerlendirilmesinde UCLA anketi kullanıldı. Kateter işlemi sonrası UCLA skoru diabetin eşlik ettiği hastalarda ortalama; $28,9^{(17,1-45,7)}$ iken diabetin eşlik etmediği hastalarda $33,1^{(17,1-51,4)}$ olarak ölçülmüştür. Kateter takılması sonrası UCLA skorlamasındaki artışın her iki grup için de anlamlı olduğu görüldü. Diabetin eşlik etmedi- ği donuk omuz tanılı hastalarda kateter takılması sonrası UCLA skorlamasındaki artışın ise diabetin eşlik ettiği hastalarda gözlenen artışa göre anlamlı olarak fazla olduğu gözlendi. $(\mathrm{p}<0,05)$.

\section{Tartışma}

Donuk omuz glenohumeral eklem hareketlerinin ileri derecede kısıtlandığı ve ağır fonksiyonel kayıplara yol açan bir hastalıktır. Her ne kadar bu rahatsızlık kendiliğinden regrese olsa da, gerek bu sürecin y1llara yayılması, gerekse en sık görüldüğü yaş grubunun aktif orta yaş olması sebebi ile ciddi sosyo-ekonomik sonuçları olmaktadır. Ağrısız ve tama yakın omuz hareketinin geri kazanımı ve hastaların normal çalışma ve sosyal yaşantılarına kısa sürede döndürülmesi büyük önem taşımaktadır ${ }^{9-13}$.

Glenohumeral eklem hareket açıklığının arttırılması için uygulanan yöntemlerden birisi de ameliyathanede anestezi altında yapılan manipülasyondur. Bu teknikle sıklıkla tama yakın hareket açıklığı elde edilmekte, fakat hastalar sonraki rehabilitasyon sürecinde bu kazanımın ciddi bir kısmını kaybetmektedirler. Bunun önüne geçmek ve fizyoterapi esnasında mümkün olduğunca geniş bir hareket arkını koruyabilmek için kliniğimizde kalıcı interskalen blok kateteri yerleştirilmekte ve hasta kontrollü aneljezi cihazı ile rehabilitasyonun daha etkin olması hedeflenmektedir ${ }^{9,14,15}$.

Diabetes mellituslu donuk omuz prognozunun daha kötü olduğu çeşitli çalışmalarda bildirilmiştir ${ }^{15-17}$. Bizim çalışmamızda da DMli hastalarda son kontrollerde EHA kazanımının DM olmayanlara kıyasla daha sınırlı kaldığı görülmüştür. Beklenildiği şekilde, bu hastaların UCLA anketi ile ölçülen fonksiyonel kazanımları da literatürde bildirilen metabolik hastalığı olmayan olgulardan daha geride kalmıştır ${ }^{18,19}$.

İnterskalen blok altında manipülasyon ve sonrasına hasta kontrollü aneljezi ile uygulanan rehabilitasyon donuk omuzun etyolojisinden bağımsız olarak hareket açıklığında ve hasta fonksiyonunda anlamlı iyileşme sağlamaktadır ${ }^{18}$. Fakat bu iyileşme DMli hastalarda, istatistiksel olarak daha düşüktür ve bu hastaların son kontrollerindeki gerek hareket açıklıkları, gerekse fonksiyonel skorları DM olmayan hastalardan istatistiksel olarak daha kötüdür.

Çalışmaya dahil edilme kriterlerini sağladığı için çalışmaya dahil olan tüm hastalarımız 40 yaş üstüdür . Bu özellik çalışmamızın kısıtlayıcı bir unsurudur. 40 yaş üstü olmak donuk omuz için bir predispozan faktördür. Dolayısıyla çalışma 40 yaş altında yetişkin hastalarda, bu risk faktörünü bulundurmayan hastalarda, donuk omuz tedavisi ve sonuçlarına yönelik yaklaşımlar için aydınlatıcılık taşımamaktadır.

Donuk omuzun ortaya çıkış nedenlerinden biri olarak omuzun immobil kalması, egzersizden kaçınılması olarak geçmektedir. Çalışmamızda hastalara kateter 
altında egzersiz uygulanmış olup minimum 6 aylık sürede tedaviye verilen sonuçlar incelenmektedir. Egzersiz uyumu zor bir süreçtir. Donuk omuz nedeniyle tedavi almış 6 aylık süreç sonrasında yeniden omuzu immobil kalmış ve yeniden donuk omuzu tekrarlamış kaç hasta bulunduğu bilinmemektedir. Takipler sırasında hastanın uyum gösteremeyip immobil kalması ve bunun net olarak değerlendirmesinin yapılamaması çalışmamızın zayıf bir yönünü göstermektedir. Hastadan kaynaklanan immo-bilizasyon elde edilen başarının uzun dönemde ne kadar kalıcı olduğu konusunda karışıklığa neden olmaktadır ${ }^{20}$.

Çalışma sonucu olarak diabetes mellitusu bulunmayan donuk omuzlu hastaların takılacak olan interskalenkateterden ve devamındaki egzersizden faydalanmaları diabetes mellitusu olanlara göre anlamlı olarak daha iyidir. Çalışmaya dahil edilen diabetik hastaların kaçının diabetinin kontrol altında olduğu bilinmemektedir. Dolayısıyla diabetin sonuçlara etki ettiği anlaşılmış olsa da diabet düzeyinin sonuçları nasıl etkilediği net olarak anlaşılamamıştır.

\section{Kaynaklar}

1. Reeves B.The natural history of the frozen shoulder sydrome.Scand J Rheumatol 1975;4(4): 193-6.

2. Duplay E.De la periarthritescapulohumerale et des raideurs de l'epaule qui en son la consequence. Arch Gen Med 1872; 20 : 513-542.

3. Codman EA.Ruptures of the supraspinatus tendon and other lesions on or about the subacromial bursa. In: Codman EA, ed. The Shoulder. Boston: Thomas Todd; 1934. 216-24.

4. Neviaser JS.Adhesive capsulitis of the shoulder.J Bone Joint Surg Am 1945; 27(2):211-222

5. Nevisaser AS, Neviaser JS.Adhesive capsulitis of the shoulder.J Am AcadOrthopSurg 2011;19(9):536-42.

6. Atici T,Şahin N, MocanMT, KaleliHT :DonukOmuz: TanıTedavi. UludağÜniversitesi Tip FakültesiDergisi 39 (3) 211218, 2013

7. Green S, Buchbinder R, Glazier R, Forbes A:Interventions for shoulder painCochrane Database Syst Rev. 2000;(2):CD001156.
8. Griggs SM, Ahn A, Green A :Idiopathic adhesive capsulitis: A prospective functional outcome study of nonoperative treatment. J Bone Joint Surg Am. 2000 Oct;82(10):1398-407.

9. Yilmazlar A, Türker G, Atici T, Bilgen S, Bilgen OF. Functional results of conservative therapy accompanied by interscalane brachial plexus block and patient-controlled analgesia in cases with frozen shoulder. Acta Orthop Traumatol Turc. 2010;44(2): 105-10.

10. Roubal P, Dobritt D, PlaczekJ. :Glenohumeral gliding manipulation following interscalene brachial plexus blockin patients with adhesive capsulitis. Journal of Orthopaedic and Sport Physical Therapy 1996;24:66-77.

11. Hannafin JA, ChiaiaTA: Adhesive capsulitis. A treatment approach.ClinOrthopRelat Res. 2000 Mar;(372):95-109.

12. NeviaserR: Adhesive capsulitis.Orthopaedic Clinics North America 1987;18:439-43.

13. Zreik NH, Malik RA, CharalambousCP:Adhesive capsulitis of the shoulder and diabetes: a meta-analysis of prevalence.Muscles Ligaments Tendons J. 2016 Jan-Mar; 6(1): 26-34.

14. Parker RD, Froimson AI, Winsberg DD, Arsham NZ : Frozen shoulder,Part II: treatment by manipulation under anesthesia. Orthopedics. 1989 Jul;12(7):989-90.

15. Ekim AA, İnal EE, Gönüllü E, Hamarat H, Yorulmaz G, Mumcu Get al. :Continuous passive motion in adhesive capsulitis patients with diabetes mellitus: A randomized controlled trial.J Back MusculoskeletRehabil. 2016 Nov 21;29(4):779-786.

16. ) Jenkins EF, Thomas WJ, Corcoran JP, Kirubanandan R, Beynon CR, Sayers AE : The outcome of manipulation under general anesthesia for the management of frozen shoulder in patients with diabetes mellitus.J Shoulder Elbow Surg. 2012 Nov;21(11):1492-8.

17. Vastamäki H, Ristolainen L, VastamäkiM:Range of motion of diabetic frozen shoulder recovers to the contralateral level.J Int Med Res. 2016 Dec; 44(6): 1191-1199.

18. Chul-Hyun Cho, MD, Ki-ChoerBae, MD, Du-Han Kim, MD:Treatment Strategy for Frozen Shoulder. ClinOrthop Surg. 2019 Sep; 11(3): 249-257.

19. Massoud SN,Pearse EO, Levy O, Copeland SA : Operative management of the frozen shoulder in patients with diabetes. $\mathrm{J}$ Shoulder Elbow Surg. 2002 Nov-Dec;11(6):609-13.

20. Boyles RE, Flynn TW, Whitman JM. :Manipulation following regional interscalene anesthetic block for shoulder adhesive capsulitis: a case series.Man Ther. 2005 May;10(2):164-71. 